coccus (Avery et al.), and then that it is the vehicle of heredity in bacteriophage (Hershey et al.). More recently, attention has been directed to the coding problem and to the mechanism of transfer of specific information from deoxyribonucleic acid to protein.

A survey of progress "from antisepsis to antibiotics" was offered by Dr. W. A. R. Thomson, who said that although antisepties had a long history, the antiseptic principle was first established by Lister in 1867, an event which led to a long and successful search for bactericidal drugs. Landmarks in that search were Ehrlich's ' 606 ', demonstrating the possibility of treatment by specific drugs, the introduction of the sulphonamides and, third, of the antibiotics. The usefulness of the sulphonamides had not yet been fully exploited and 'the antibiotic rush' of the fifties may in retrospect be seen as fundamentally unscientific. The isolation of 6 -aminopenicillanic acid in 1959 marked the opening of a new and genuinely scientific era in antibiotic research. Dr. Thomson concluded with a word of caution; indiscriminate use of antibiotics had upset the balance of Nature and "the mass-murder of micro-organisms" was not necessarily a good thing. The careful use of antibiotics combined with immunotherapy offered a wiser course for the future.

Dr. F. L. Rose took one of the important developments of the same period for closer investigation in his account of the origin and rise of the synthetic drugs. With one or two exceptions, he said, all the medicaments available until the mid-nineteenth century were natural products. At that point in time, the coincidental discovery of the first synthetic dyestuffs and of micro-organismal origin of infectious diseases soon brought about a rapid change. The former because it caused an almost explosive growth of synthetic organic chemistry in a way which invited its direction into biological pathways, and the latter because it provided the motive and means for examining the effect on disease of the compounds poured out by the chemists. Thus the evolution of the modern antimalarial agents can be traced back directly to the observed staining of the malaria parasite by methylene blue. Methylene blue is a derivative of phenothiazine, itself widely used as an anthelmintic, and from which stem some of the most effective tranquillizing agents. Similarly, the modern trypanocides owe their beginning to the feeble therapeutic action shown by the early direct cotton dyestuffs, and the medicinal properties, initially antiseptic but later trypanocidal, found in the first azine and cyanine dyestuffs. Likewise, the appear. ance of the first azosulphonamide drug coincided with interest in the use of the sulphonamide group as a component of azo dyestuffs. These drugs were additionally important in that their technical develop. ment directed attention to the sulphones, now widely used in leprosy, while minor side effects were ex. ploited to produce highly effective diuretic and hyperglycæmic agents.

A dinner was held in Apothecaries' Hall when the guest of honour was Sir Howard Florey, and the president of the Chemical Society, Sir Alexander Todd, gave the after-dinner address. He discussed the long-standing relationship between chemistry and medicine and stressed that the indebtedness was mutual, for medicine and its neods had provided a very great impetus to the growth of chemical research. He found in the title of the congress a reflexion of the orthodox separation of the basic sciences, a situation which was probably incapable of fruitful development. Many important problems required workers with many kinds of scientific skill, and although research institutes may provide this kind of team, research was still best undertaken by the universities. The barriers between departments must be broken down to enable the constant influx of young rainds to cross the barriers between the sciences.

The papers given at the congress are to be published in volume form. It has already been decided that the meeting next year will be held in London during September $27-28$, and will have as its theme "The History of British Hospitels". F. N. L. POYNTER

\title{
THE AUSTRALIAN NATIONAL RADIO ASTRONOMY OBSERVATORY
}

\begin{abstract}
USTRALIA made an early start in radio A astronomy at the end of the Second World War, and has remained ever since among the leading countries in this rapidly advancing field. Australian radio astronomers now possess a radio telescope which is the foremost of its type in the world at the present time-a 210-ft. steerable paraboloid, with a surface accuracy of a few millimetres.

The new telescope, which is located at Parkes, New South Wales, 230 miles west of Sydney, was commissioned on October 31 by the Governor-General of the Commonwealth of Australia, His Excellency the Right Hon. Viscount De L'Isle, and it will be operated by the Division of Radiophysics of the Australian Commonwealth Scientific and Industrial Research Organization. The telescope is the first instrument of the Australian National Radio Astronomy Observatory, which was inaugurated at the same time.
\end{abstract}

The plan for a large steerable paraboloid originated seven years ago, when the first specifications were drawn up by Dr. E. G. Bowen, Chief of the Organization's Division of Radiophysies. His vision and enthusiasm have been largely responsible for the successful completion of the project.

A large donation from the Carnegie Corporation (250,000 dollars) enabled the design work to start, and other generous donations were afterwards received from the Rockefeller Foundation (357,000 dollars), and from a number of private donors in Australia. These sums were matched on a pound-for-pound basis by the Australian Commonwealth Government. The total cost of the project has beer about $£ 800,000$

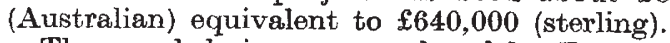

The novel design was produced by Freeman, Fox and Partners, consulting engineers, of London, with Mr. Gilbert Roberts in charge of the responsible group. The construction was carried out by Maschin. enfabrik Augsburg-Nürnberg, A.G., of West Germany, which submitted the best tender, both in price and delivery time, and was awarded the prime contract. The principal sub-contractors were Askania Werke, 
of West Berlin, Associated Electrical Industries, Ltd., of Manchester, and Concrete Constructions Pty. Ltd., of Sydney.

The telescope is mounted in azimuth-altitude style, on a single concrete tower, which also contains the telescope controls and the radio receivers. The whole structure rotates in azimuth on a circular track which is set into the top of the concrete tower; a range of $450^{\circ}$ is available, limited only by the cable. twisting requirements. The altitude motion, between zenith angle $0^{\circ}$ and $60^{\circ}$, is obtained through a large rack gear. A wide range of speeds is available in each co-ordinate.

A unique feature of the instrument is the control system for driving the telescope in equatorial coordinates. The heart of this system is a small 'master equatorial' unit, which is mounted at the intersection of the altitude and azimuth axes, on a special concrete support, completely isolated from the rest of the structure. This unit controls the motion of the telescope through a servo system which contains an optical link.

The 'dish' is supported by a structure of 30 radial trusses, which carry a system of ring girders and two sets of intersecting spiral members. The reflecting surface consists of wire mesh, with wires $1 \mathrm{~cm}$. apart, except for the inner $54 \mathrm{ft}$., which is covered with steel plates. The inner solid section was adjusted to fine limits during construction; but the individual panels of the mesh surface carry screw adjustments, which can be reset at any stage.

The aerial feeds and pre-amplifiers are supported by a large cabin, which is mounted on a tripod above the reflector. The cabin is large enough to carry test equipment and observing personnel during special tests, though normal operations will of course be controlled from below. There are a lift in one tripod $\log$ and ladders in the other two, for access to the focus cabin.

The telescope is now structurally complete, and is at present undergoing a rigorous series of tests, through theodolite surveys of the shape of the dish and radio observations of cosmic sources. Some progress performance figures are now available, and very satisfactory results are being obtained.

The original specification called for a surface accuracy of $\pm 9 \mathrm{~mm}$. With the dish looking vertically, most of the adjustment points on the mesh surface are within $2 \mathrm{~mm}$. of the required parabolic shapewith additional deviations of the same order inside the individual panels.

Some early figures have been obtained for the radio performance at wave-lengths of 21 and $10 \mathrm{~cm}$. At $21 \mathrm{~cm}$., the beam-width is $13 \frac{1}{2} \mathrm{~min}$. of arc or less. and the side-lobe level is in the region of $-25 \mathrm{db}$. At $10 \mathrm{~cm}$., the first measurement gave a beam-width of $7 \frac{1}{2} \mathrm{~min}$., and the side-lobe level is again very low. Moreover, these figures were obtained with the dish $40^{\circ}-60^{\circ}$ from the zenith, where any distortions would be at their maximum.

On the opening day, there was a widely representative gathering of nearly 500 guests at the Observatory. many of whom had come from Sydney, Canberra and Melbourne in a special airlift. Before the ceremony, the visitors inspected the structure, and then were shown a large photographic and descriptive display which had been specially set up for the occasion.

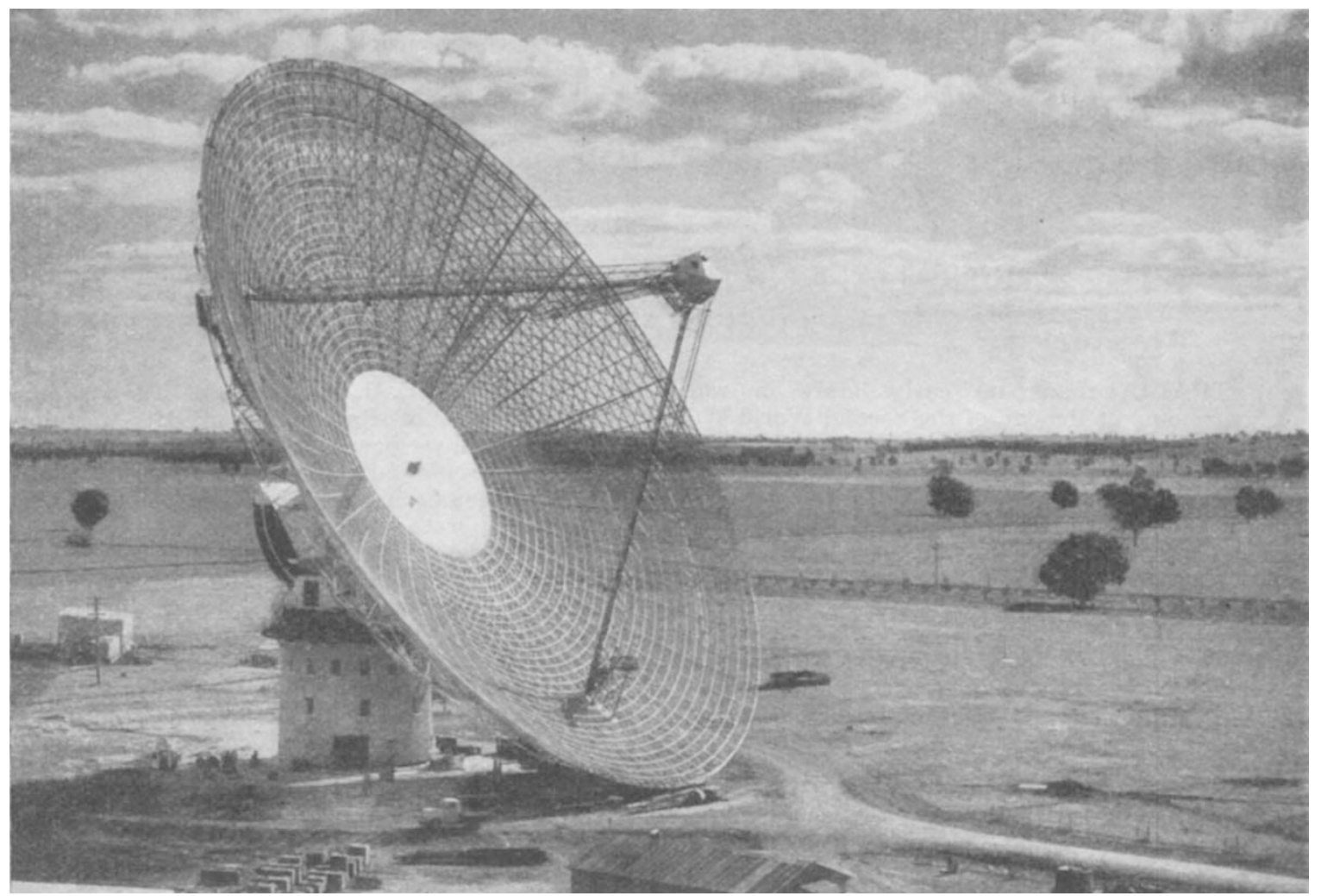

Fig. 1. The completed telescope, tilted down to its lowest position, $60^{\circ}$ from the zenith 
After being welcomed by Dr. F. W. G. White, Chairman of the Commonwealth Scientific and Indus trial Research Organization, the Governor-General began by reading a message from H.R.H. The Duke of Edinburgh:

"The development of radio astronomy has been one of the great events of modern Science, and the scientists of C.S.I.R.O. have played a leading part in this important work. Their studies of the Sun and the exploration of extraterrestrial space to the remotest parts of the universe have gained the admiration of astronomers everywhere and have brought great credit to Australia.

"To-day the radio astronomers of Australia are to be rewarded by the inauguration of a magnificent radio telescope which will enable them to penetrate still further the secrets of the cosmos. This occasion marks the culmination of much planning and hard work and I send you my best wishes for the success of your investigations with this new instrument."

His Excellency then discussed the way in which realization of this "Giant Radio Telescope" had come about as the result of a happy conjunction in Australia of several distinct, but all of them propitious, cireum. stances. "Thus conceived and encouraged, the enterprise has leapt forward at a pace which I found both admirable and refreshing." He closed in whimsical mood with a quatrain which "seemed to float into my mind from an extra-planetary source":

$$
\begin{aligned}
& \text { "Twinkle, twinkle radio star. } \\
& \text { We can't see you : you're too far. } \\
& \text { Now we hear from outer space } \\
& \text { How you run your cosmic race." }
\end{aligned}
$$

The next speakers were Dr. The Hon. D. A. Cameron, the Minister-in-Charge of the Commonwealth Scientific and Industrial Research Organization, and The
Right Hon. Lord Casey, who was Minister-in-Charge of the Organization during the early critical stages of the project, and has continued his connexion with it as chairman of the Radio Astronomy Trust.

At this stage the Governor-General performed the commissioning ceremony, and a large Australian flag was broken out above the focus cabin, the highest point of the structure. Unfortunately, wind gusts of more than 50 m.p.h. interfered with a plan to tilt the dish down towards the assembled erowd. The area is normally very calm, which in fact was one of the ressons for its choice; but on this ceremonial occasion the weather was unkind, with wind-speeds at their highest level for several years.

Dr. Bowen closed the proceedings by outlining some of the plans for the future use of the instrument. A number of important observational programmes are ready to start as soon as the present period of extensive tests is completed. These include work on the identification of extragalactic sources, and studies of galactic structure, the Magellanic Clouds, bright hydrogen regions, and the planet Jupiter.

The new instrument will make a powerful addition to the facilities available to the Australian radio astronomers; but it is also a notable gain for the astronomical world at large. To quote Dr. Bowen's concluding remarks: "When the first urgent tasks of the next few months have been performed, it will be thrown open to astronomers from every part of the world with woithwhile problems to attack. We pledge ourselves to work in close collaboration with our fellow scientists from any country and will make this Observatory a rallying point for equipment and information, for techniques and intellects which, together, will lead to further great advances in the seience of astronomy".

\section{OBITUARIES}

Prof. Robert Boutflour, C.B.E.

Prof. Robert Boutflour, who had resigned as principal of the Royal Agricultural College in 1958, died on October 27 in Cirencester at the age of seventy-one. He was educated at Barnard Castle School and Armstrong College-now King's College, Newcastle upon Tyne.

Boutflour's first appointment was lecturer in agriculture with the Lancashire County Council; this was followed by a similar post in the University of Ieods, and in 1921 he was appointed agricultural officer for the County of Lindsey. In 1922 he was made chief agricultural officer to the Wiltshire County Council, where he remained until 1926, when he was appointed the first and last national director of dairy husbandry.

$\mathrm{He}$ is best known for his work on the breeding and management of dairy cattle. This he started in Wiltshire, where it was realized that he was a man of sound progressive ideas, and in fact, many years ahead of his time, which is now proved inasmuch as his ideas are now accepted in general practice. His fame extended abroad as well as at home, and he is well known to many farmers of the territories he visited in the United States, Canada, Kenya and Australia.

While national director of dairy husbandry, he was attached to the Harper Adams Agricultural College, where he established his famous Friesian herd of dairy cattle. This enterprise proved to be an outstanding success and enabled him to put into practice those points of management that he had so strenuously advocated to farmers throughout the United Kingdom.

Boutflour was an impressive author and wrote many works on farm management in general, and the subject of dairy cattle in particular. While his success as a scientist was largely due to his keen powers of observation, coupled with patient and inspired reasoning, his ability to impress audiences or individuals was the result of his enthusiasm, alert mind and logical arguments coupled with a quick wit. In character and speech he was always most forthright, but his caustic remarks were usually offset with a characteristic twinkle in his eyes.

His appointment as principal of the Royal Agricultural College in 1931 gave him the necessary scope for his ability in organization and administration. and particularly to associate with young people, to whom he was always willing to give advice and encouragement. When he retired from the principalship in 1958 he had the satisfaction of knowing that during his term of office he had increased the number of students from 48 to more than 450 .

During the Second World War, as executive officer for food production in Gloucestershire, he adopted many revolutionary methods to increase the output of food. One of his most daring ventures was to 